\title{
A Case Study of Job Access and Reverse Commute Programs in the Chicago, Kansas City, and San Francisco Metropolitan Regions
}

\author{
J.S. Onésimo Sandoval, St. Louis University \\ Eric Petersen, Cambridge Systematics \\ Kim L. Hunt, O-H Community Partners, Ltd.
}

\begin{abstract}
The 1996 federal welfare-to-work legislation generated significant debate regarding what role public transportation should play in facilitating lower welfare rates. Given this debate, transportation has been called the "to" component of welfare-to-work. In this paper, we present findings from three case studies that examine job accessibility and reverse commute transportation programs in the Chicago, Kansas City, and San Francisco metropolitan regions. We explored how institutional and/or grassroots support prevented or fostered the innovation and implementation of non-traditional Access-to-Jobs and Reverse Commute (JARC) programs. Our findings suggest that institutional support and grassroots support are necessary ingredients for the implementation of innovative transportation programs for low-income families.
\end{abstract}

\section{Introduction}

In 1996, Congress passed a sweeping welfare reform law called the Personal Responsibility and Work Opportunity Reconciliation Act (PRWORA), which replaced the existing welfare entitlement program. One aspect of PRWORA that 
has impacted urban and rural transportation services was the requirement that welfare recipients find full-time employment. Congress recognized that the poor faced a major spatial mismatch in terms of where they lived (typically, central cities) and where new employment opportunities were located (generally, the outer suburbs) (Kasarda 1988; Gomez Ibanez 1984; Sanchez et al. 2003). The spatial mismatch makes commuting to suburban job centers difficult (to say nothing of finding a new job in the first place), but particularly challenging for workers (or potential workers) who do not have access to a car. One of the major obstacles welfare mothers faced as they tried to find work was an insufficient transportation infrastructure to overcome the spatial mismatch (Blumenberg 2002; Blumenberg and Manville 2004; Cervero 2004; Ortoleva and Brenman 2004; Sanchez et al. 2004). In response to inadequate transit access and service, several policy programs were designed to provide and fund reliable transportation for low-income families. ${ }^{1}$ The underlying goal for all these programs was to provide flexible transportation to increase economic opportunity. The primary funds for transportation services for Temporary Assistance for Needy Families (TANF) recipients came from TANF (user-side subsidies), Welfare-to-Work Grants (Department of Labor), and Bridges-to-Work (Blumenberg 2002; Government Accounting Office 1998). However, the U.S. Department of Transportation (DOT) proposed the creation of a much larger $\$ 600$ million Access-to-Jobs program to be administered by the Federal Transit Administration (FTA) (Government Accounting Office 1998). The Transportation Equity Act for the 21st Century (TEA-21) established the Accessto-Jobs and Reverse Commute (JARC) program in 1998 and authorized up to $\$ 750$ million over five years to implement the program.

One important aspect of the JARC program was that TEA-21 limited funding of Access-to-Jobs programs to 50 percent of each grantee's project, unlike the 80 percent match generally available for highway projects and New Start transit projects (Government Accounting Office 1998). The policy incentive was designed to encourage local, regional, and state agencies to collaborate with each other as they designed transportation policies. Another important aspect of the policy was that JARC was designed to be a competitive granting process. The rationale behind this aspect of the program was to fund the most innovative and effective transportation programs for low-income families. Policy makers conceded that "existing public transportation systems cannot always bridge the gap between where the poor live and where jobs are located" (Government Accounting Office 1998). The policy incentive strongly encouraged traditional transportation agencies to work with local grassroots organizations in an effort to explore all non-traditional trans- 
portation alternatives to the fixed route or existing mass transit systems (Government Accounting Office 1998).

There is no question that the JARC programs distributed a large sum of transportation funding targeted towards low-income populations. However, it is not clear if this funding was effective in allowing individuals to move into the workforce, particularly since the evaluations conducted by the Government Accounting Office (GAO) focused more on the process of awarding JARC funds rather than program outcomes. Moreover, the lasting impact of the JARC funds is not clear. While there was hope that JARC funds would serve as seed money to get deserving projects off the ground, program implementers seemed to accept that many projects were experimental and would not be made permanent. This raises a legitimate point about the long-term sustainability of JARC programs.

The critics of JARC were right to ask whether JARC programs were merely a cosmetic policy remedy or if the programs truly were designed to eliminate the deep structural inequalities built into the existing mass transportation systems. If the primary goal was the elimination or at least reduction of structural inequality, then phasing out federal funding sent the wrong message, unless one truly believed that, with one major push, people would leave and remain off of welfare. In reality, few metropolitan regions have the fiscal resources to maintain these programs without additional federal support. Pittsburgh is only one of many cases where budgetary crises have led to the proposed elimination of JARC programs (Curry 2007).

An equally important dueling tension emerges as to whether JARC is a transportation program or employment program (Wachs and Taylor 1998). If JARC is viewed as a transportation program, the goals and objectives will obviously be different compared to designing programs, goals, and objectives as an employment program, which would also translate into evaluation criteria (i.e., focusing on the number of people who can remain off welfare due to using the services and not narrow fiscal questions about ridership recovery ratios [Petersen and Sermons 1996]). This dueling tension was and is a reality in many regions. Without reliable transportation access, many low-income families simply cannot maintain stable employment. Thus, innovative transportation programs not only provide reliable transportation services, but also are the umbilical cord to economic mobility for many low-income families.

In this study, the objective was to examine how grassroots and institutional support shaped regional JARC transportation policies. Of special interest was how 
these processes of support shaped innovation and implementation of transportation policies within the Metropolitan Planning Organizations (MPOs). To the extent that MPOs design new transportation policies with the support of the institutional and grassroots organizations, there will be prima facie evidence that both types of support are necessary to creatively develop and implement transportation policies for low-income populations.

\section{Background}

This study follows the lead of Blumenberg, Cervero, Sanchez, and Schweitzer, who paved a path for scholars to study the effectiveness of transportation programs to provide reliable private mobility and economic opportunity (Blumenberg et al. 2003; Cervero et al. 2002; Sanchez and Schweitzer 2008; Blumenberg and Schweitzer 2006). This literature is followed in drawing on three key themes to frame the inquiry: (1) innovation with JARC programs; (2) devolution of authority and decision making to grassroots organizations; and (3) inter-agency collaboration (i.e., institutional support).

First, there is an ongoing debate if federal money should be used to buy cars for low-income families. The assumption prior to the 1996 welfare-to-work law was that federal money should be used for public transportation. Welfare bureaucrats were working with a similar assumption. For example, welfare families were sanctioned off of welfare if they owned a car worth more than $\$ 1,500$ because it was deemed an asset (Ong 1996). However, a tremendous amount of research shows the advantages of mobility by car versus public transportation for welfare recipients (Cervero and Tsai 2003; Ong 1996; Ong and Blumenberg 1998; O'Regan and Quigley 1998; Raphael and Rice 2002).

Second, building on the theme of collaborative policy design, the federal government encouraged non-traditional transportation providers to submit applications for JARC funding. However, several scholars have pointed out that this process of devolution had the potential to lead to a "race to the bottom," where nontraditional transportation providers would compete with each other in cutting costs and ultimately services (Lieberman and Shaw 2000; Schram 1998). The more important aspect of the devolution policy incentive was the real possibility that the large traditional transportation agencies would give meaningful authority and power to non-traditional transportation providers (i.e., grassroots organizations). 
Finally, in a post welfare-to-work era, working on a transportation problem alone was not looked on favorably. To receive the new federal funds, Congress required transportation agencies to collaborate with each other to prevent duplication of services, capitalize on the strengths of each agency, and build on the collective strengths of the new partnerships. This new policy incentive assumed that agencies had similar goals and objectives. In addition to typical bureaucratic turf wars, the reality is that there were and are different visions regarding the goals, objectives, and definitions of success for JARC programs, which greatly complicates coordination between agencies; therefore, impacting the magnitude of institutional support for any given JARC program (Blumenberg 2002).

\section{Theoretical Framework}

This study of implementing JARC by MPOs could be grounded in a variety of theoretical perspectives, including rational choice theory, functional theory, or collective rationality theory (Douglas 1986). ${ }^{2}$ We believe collective rationality theory is the most appropriate framework to compare and contrast the collective effectiveness within the MPOs as they responded to the prospects of tapping into federal JARC funding. The amount of collective effectiveness an MPO demonstrates in achieving organizational goals arises out of organizational culture. This paper highlights how important institutional and grassroots support was for MPOs. Analyzing how MPOs responded to the opportunity to develop JARC programs (and access the associated federal funding) not only provides insight into the culture of the MPOs, but into how effectively they integrated and activated different social institutions and social processes, leading to different policy outcomes. The collective effectiveness within the MPO does not exist in isolation, but develops in response to the collective need. Therefore, if the people in the region are excited about new alternative transit programs that address a specific need, then actors within the MPO will respond to the excitement and funnel this energy to formulate creative policy options. Thus, the MPO will engage in collective action and do what is "best" for the region rather than simply what is best for the MPO (Douglas 1986). ${ }^{3}$

This collective effectiveness can take many forms within the organization. Thus, the conceptual advance presented in this paper is our framing of effectiveness within the institution and the effectiveness between grassroots organizations and institutions. Institutional effectiveness and grassroots effectiveness are essential factors that augment trust among all actors, thereby increasing the capacity to 
perform at higher and more creative levels (Altshuler and Behn 1997). The end result will be the creation of social processes that will produce innovation in transit services for low-income families, which will be implemented for the greater good of the region.

\section{Institutional Support}

The first conceptualization of effectiveness is institutional support. Effectiveness will increase with increased levels of institutional support from the MPO, regional, state, and national-level politicians who placed JARC funding as a priority for the region. This was particularly true as the game changed and the JARC funding process moved from being proposal-driven to one where nearly all the funds were earmarked. If a region did not convince its Congressional delegation to put in for earmarks, its share of JARC funds dropped sharply. Thus, any desire to creatively work with JARC declined. Institutional support is extremely important in determining if the MPO feels that it can respond to the transportation needs of the poor in creative and more efficient ways with a sense of cooperation with alternative transportation providers. If the MPO has no support, then it sees alternative transportation providers as competition, in the sense that transportation funding may ultimately be diverted from more general transportation problems that it feels are more central to its mission. The end result is that there will be little collective efficacy to change the culture of the MPO (DiMaggio and Powell 1991).

In the case of JARC, institutional support at the federal level can be measured by the amount of earmarking activity on the part of the region that occurred in fiscal year 2003. The impacts of institutional support (i.e., how well this support was translated into the internal processes of the MPO) can be measured in a variety of ways: (1) efficiency, (2) cooperation, (3) creativity, and (4) implementation. By efficiency, we are looking for institutions that decide to work outside of the normal bureaucratic structures to deliver JARC programs. We are interested in cooperation because the early literature on bureaucracies indicates that they emerge because of competition (Weber [1922] 1978). MPOs with little support will maintain ironclad policy choices, and they view the diversity of transportation options as threatening. In contrast, MPOs with high institutional support will view the grassroots organizations as an asset to achieving policy goals that can be achieved within their organization with efficiency. These MPOs will create processes that will cultivate a new discourse of creative policy options to meet 
the unique demands of the poor. Furthermore, these processes will foster a policy environment that will be conducive to policy implementation.

\section{Grassroots Support}

The second conceptualization of effectiveness is grassroots support. Grassroots support is defined as non-profit and non-traditional transportation organizations. We believe that grassroots support represents a collective decision (by community members or organizations) that is not made in isolation, but rather in response to an opportunity to work in a changing environment (e.g., JARC) (Singh et al. 1991). One of the unique aspects of the JARC program was that it encouraged innovation and support from grassroots organizations. The potential grassroots involvement in a region could be orderly or chaotic, depending on how many organizations actually submitted an application. The view of grassroots organizations and MPOs has been viewed as a confrontational relationship, where the MPO has to continue its policy implementation in the face of conflict (Forester 1989). However, JARC had the potential to change this confrontational relationship with grassroots organizations because the premise of JARC was to involve grassroots organizations from the very beginning, where these organizations would be co-designers and co-implementers of transportation policy. The goal of the MPO was to coordinate the grassroots activities for the collective good of the region and to create an environment that produced a partnership between the MPO and community organizations that was conducive to creative transportation policies and innovative implementation strategies. Grassroots involvement in the JARC process was generally straight-forward to measure because the number of non-profit and nontraditional groups that pushed for JARC funding or that played an active role in the process were counted.

\section{Research Design and Data}

We developed an analytical typology of support that framed our research design and methodology. The two dimensions were levels of institutional support and grassroots support. At the beginning of our discussion, we felt it was important to study at least three regions so that we could observe variation in institutional and grassroots support. We felt it appropriate that each region score highly in at least one dimension due to our concerns that a region that was low along both dimensions might not pursue any JARC funding and would essentially be a null case for 
our study. After much deliberation, the Kansas City, Chicago, and San Francisco Bay metropolitan regions were selected based on initial archival research. Preliminary archival research indicated that the three regions selected filled the appropriate cells in our typology, so we undertook a more detailed analysis of each region. We believe that examining variations in institutional and grassroots support offers an important analytical lens to study innovation and the eventual implementation of JARC programs. Figure 1 reflects the analytical typology, as well as the initial assessment of where the cases should be located. This typology allowed us to frame our inquiry around the role that institutional and external support had in shaping JARC programs.

\begin{tabular}{|l|l|l|l|}
\hline \multicolumn{2}{|c|}{} & \multicolumn{2}{c|}{ Grassroots Support } \\
\cline { 3 - 4 } \multicolumn{2}{|c|}{} & High & Low \\
\hline Institutional Support & High & San Francisco & Kansas City \\
\cline { 2 - 4 } & Low & Chicago & \\
\hline
\end{tabular}

\section{Figure 1. Institutional and Grassroots Support for JARC Programs}

Our first hypothesis was that the inertia of traditional bureaucratic transportation institutions would not foster inter- or intra-agency cooperation because of lowinstitutional support regardless of grassroots support (Government Accounting Office 1999). Our second hypothesis was that agencies with low institutional support would shy away from creative non-traditional transit programs (e.g., private mobility). However, MPOs with high grassroots support would navigate to these programs because the grassroots organizations would be more efficient in service delivery. Our final hypothesis was that agencies with high institutional support would favor devolution of authority or decision making. By using these hypotheses as our guidelines, the analysis of JARC at the regional level represents an exemplary case to study how some institutions create new processes that hamper innovation and how other institutions create new processes that foster innovation.

\section{Data Collection Strategy}

We decided that the analysis of three regions would be framed around a casestudy design. Data were collected in three distinct phases. First, we attended local meetings where key stakeholders were present. The meetings were sponsored by the MPO or the grassroots organizations. This allowed us to observe who attended the meetings and who participated in the public discussions. Second, we interviewed several individuals from the respective MPOs and grassroots organiza- 
tions. Most of the interviews were done face-to-face. However, a few interviews were conducted by telephone because of logistical issues. The interviews were not taped, but we took notes that highlighted the important themes that emerged from the interviews. Finally, we collected published reports, newspaper articles, and public documents that were related to JARC programs in each region. The documents were systematically organized to study innovation, implementation, grassroots support, and institutional support.

\section{The Chicago Case}

The Chicago metropolitan area was well positioned to qualify for JARC funding when the program was announced. Due to pressure from community groups, the Chicago Area Transportation Study (CATS), the MPO for the region, established the Community Mobility Task Force. This task force was created to study the mobility needs of the poor, particularly access to job opportunities for the unemployed. ${ }^{4}$ In 1998-99, the Task Force had 21 members, including the Illinois Department of Transportation (IDOT), the Illinois Department of Human Services, the City of Chicago, the Councils of Mayors, the three public transit agencies, private transportation providers, social service agencies, and community based organizations (e.g., The Center for Neighborhood Technology [CNT]).

As the FTA worked on guidance, the Task Force continued to meet and consider early candidates for JARC funds, including an expansion of the Metra Shuttle Bug service and a bus service to take residents from the South suburbs to industrial jobs around O'Hare Airport (Chicago Area Transportation Study 1998). In October, the FTA guidance for the program was released. At that time, MPOs were informed that the applications for JARC funds were due by December 31, a very short lead time for such an important program, which was then cut further by two weeks due to the need to have the grant proposal ready for approval by the CATS Policy Committee (Chicago Area Transportation Study 1998). In October, the Task Force hosted a workshop for non-traditional transportation providers to explain the program and to solicit proposals for JARC funding. One general finding was that participation in the Task Force was erratic. Many of the core task force members attended nearly all meetings, but smaller transit providers or average citizens appeared only when there was a chance that new projects would be selected for inclusion in an official CATS submittal. Participation dropped off as it became clear that new projects would be shut out due to the high levels of federal earmarking. 
It became apparent to the Task Force that the local match requirement (a full $50 \%$ ) was an insurmountable barrier for the vast majority of the small transportation companies unless they had partnered with a government agency, such as the City of Chicago or DuPage County. Of the 14 projects that were submitted, those projects not connected to a government agency were often grouped into a catchall project called the Chicago Area Job Access and Transit Enhancement Plan, which would be administered by the CTA, Metra, and Pace.

After evaluating the proposals, the Task Force pulled together its grant proposal. The proposal included eight first-tier projects at a total cost of $\$ 2.5$ million, with $\$ 1.5$ programmed for the Chicago Area Job Access and Transit Enhancement Plan. There were three second- and third-tier projects, which were requests for second year funding for several of the first-tier projects (Chicago Area Transportation Study 1998). It appears that when the FTA analyzed the grant proposal, the agency ran down the list and accepted the first five-first tier projects for a total grant of $\$ 2.2$ million and dropped the remainder, for the award amounts for FY 1999 closely matched the CATS' figures in the proposal.

Northeastern Illinois continued to receive a considerable share of JARC funds for FY 2000 through FY 2002. In all three years, the total grants were over \$2 million. However, due to Congressional earmarking, CATS and the Community Mobility Task Force had less and less control over how the funds were allocated. For example, of the $\$ 2.2$ million for FY 2000, CATS had only $\$ 1$ million to distribute. The funds to be spent on direct transportation services for the poor were cut roughly in half, though of course the region still had a considerable sum of unobligated funds from FY 1999. The funding picture was similar for FY 2000, where roughly $\$ 2$ million was available for the Chicago metropolitan region, but $\$ 1.5$ million had come from various earmarks. By FY 2002, nearly 90 percent of JARC funds were allocated according to earmarks, though the Chicago area still won some of the competitive grants, but by FY 2003, the entire federal JARC program had been earmarked. Chicago's share dropped to under $\$ 0.5$ million (See Table 1). When examined on a per capita basis, the Kansas City and San Francisco regions received nearly four times the JARC funding as Chicago, which can be attributed almost entirely to earmarks. This is a curious outcome, given that, at both the central city level and regional level, Chicago's poverty rate exceeds that of Kansas City or San Francisco. 


\section{Table 1. JARC Funding (\$ millions) in Metropolitan Chicago, Kansas City and San Francisco}

\begin{tabular}{|c|l|c|c|c|c|c|c|c|c|c|}
\hline \multicolumn{2}{|c|}{} & FY99 & FY00 & FY01 & FY02 & FY03 & FY04 & FY05 & FY06 & Total \\
\hline \multirow{4}{*}{$\begin{array}{c}\text { JARC } \\
\text { Funding }\end{array}$} & Chicago Metro & 2.2 & 2.2 & 2.1 & 2.4 & 0.5 & 0.5 & 0.4 & 3.5 & 13.8 \\
\cline { 2 - 11 } & Kansas City Metro & 1.0 & 1.0 & 0.0 & 1.0 & 2.7 & 3.0 & 0.8 & 0.5 & 9.9 \\
\cline { 2 - 11 } & San Francisco Metro & 0.6 & 1.1 & 0.4 & 6.1 & 4.2 & 6.0 & 3.8 & 1.4 & 23.5 \\
\hline \multirow{2}{*}{$\begin{array}{c}\text { JARC } \\
\text { Funding } \\
\text { per capita } \\
\text { (in \$) }\end{array}$} & Chicago Metro & 0.25 & 0.24 & 0.23 & 0.26 & 0.05 & 0.05 & 0.04 & 0.37 & 1.49 \\
\cline { 2 - 11 } & Kansas City Metro & 0.54 & 0.54 & 0.00 & 0.53 & 1.41 & 1.55 & 0.39 & 0.27 & 5.26 \\
\cline { 2 - 11 } & San Francisco Metro & 0.15 & 0.26 & 0.09 & 1.47 & 1.00 & 1.45 & 0.92 & 0.32 & 5.67 \\
\hline
\end{tabular}

Note: FY 2003-05 Chicago figures does not include statewide Illinois Ways to Work funding Source: CATS, MARC, MTC, US GAO, US Census

One CATS official responsible for oversight of the Community Mobility Task Force's proposal commented that the heavy use of earmarks in the last years of the program made it a different program. Most agencies nationwide that asked their Congressional representatives for JARC earmarks did receive them, but in the Chicago region only PACE, UIC, and DuPage County made that effort. This person did not speculate on why CTA and Metra did not seek out earmarks, though it could well be that those agencies were already asking Congress to fund massive infrastructure projects that had a higher internal priority than the JARC programs.

In giving a general evaluation of the program, one local observer from the Center for Neighborhood Technology felt that the JARC program was very important for simply trying to meet the transportation needs of the poor. This person felt that there was considerable pent-up demand for non-traditional transit service specifically targeted at welfare recipients and other low-income individuals. This person would have liked more flexibility in the program, particularly when it came to the FTA requirements, but a more critical need was to ensure that there was ongoing support for worthy JARC programs, since agencies generally were not willing to commit themselves to sustaining reverse commute programs in the absence of external funds. The program should have been structured to guarantee the operating funds for a longer time in order to build demand for transit in the region; even a three-year pilot program was not really long enough. 


\section{The San Francisco Case}

The situation in the Bay Area was similar to that in Chicago in terms of the MPO applying for a large JARC grant to support a transit-oriented plan. In addition, in both regions, a fair number of stakeholders took part in the process. After the passage of California's CalWORKs law in 1997, the Metropolitan Transportation Commission (MTC) took a leadership role to address the transportation barriers that poor women would encounter as they looked for work. Because MTC is the transportation planning, coordinating, and financing agency for the San Francisco Bay region, they were in a unique position to lead the planning process and identify regional transit problems and solutions.

In 1998, with the support of MTC, AC Transit started an experimental bus line that operated during evening hours to connect welfare recipients in Richmond to employment centers that had job openings for shift workers. This was the first program enacted that specifically addressed a key transportation barrier for CalWORK recipients. The goal of the service was to provide more transit access to Richmond, which had one of the highest concentrations of CalWORK recipients, to areas that had a shortage of entry-level employees. In the eyes of MTC and AC Transit, the "OWL" service was a success because it was providing a service to residents and the service was being used by the residents. Success in this context is relative. In fact, when asked to define success, the officials from MTC simply stated that the "OWL" service was a success because it was used by underserved low-income populations regardless of the cost. ${ }^{5}$

MTC coordinated all the JARC applications by grassroots organizations to ensure that there were no duplications in services. One of the most innovative programs funded with JARC funds was the regional JARC program, the Low-Income Flexible Transportation program (LIFT). LIFT provided funding to fill transportation gaps that had been identified through local and regional welfare-to-work planning workgroups with grassroots organizations. One major goal of LIFT was to secure JARC funding for grassroots organizations to ensure that these organizations had the opportunity to be co-planners, co-designers, and co-implementers of innovative JARC programs.

Taking advantage of JARC's flexibility, in the first round, MTC funded two projects designed to provide transportation for children and one project designed to provide non-traditional transportation access. One reason there was a low number of these projects was that they required more time and coordination from MTC staff. Another reason there was a low number of applications was because it took 
a significant amount of time to clarify JARC program objectives and regulations and identify resources that could be used to ensure that the program would work. Even though half of the LIFT programs were for bus line improvements, MTC recognized that public transit could not meet the needs of all CalWORK recipients (Fol et al. 2007). This was a new and awkward position for MTC given that their overall mission is to promote public transit (Fol et al. 2007; Blumenberg et al. 2003). By funding two car programs and one vanpool program in the second round of LIFT funding, MTC took a step towards increasing the diversity of transit options for low-income populations. Studies have consistently shown that welfare recipients that own a car are more likely to leave the welfare rolls and find sustainable employment (Lucas and Nicholson 2003; Cervero et al. 2002; O'Regan and Quigley 1998; Blumenberg 2000; Cervero et al. 2002; Ong and Blumenberg 1998; Ong 1996; Raphael and Rice 2002). Another study found that even those welfare recipients who found employment using public transportation would immediately buy a car when they have saved enough money for the down payment (Blumenberg 2000). ${ }^{6}$

More significantly, MTC increased funding for transportation services specifically targeted at children of low-income families. These types of services have become increasingly important as single women with children try to reduce the number of multi-leg work commutes to simple one-leg commutes, thus reducing the amount of time they have to spend on commuting and transferring from bus line to bus line to get from their home to work. Perhaps one of the most innovative uses of LIFT funding was a program in Sonoma County called Long-Term Transportation Solutions. One component of this program was teaching welfare recipients how to make complex trips via public transit more efficient. Many entry-level job openings for Sonoma County residents are located in San Rafael in Marin County. Getting to these jobs via public transit is possible, but bad trip planning can result in a passenger spending unnecessary hours on public transit. Learning how to read a transit system and plan appropriately for bus transfers is essential for residents in the North Bay, where bus service is not as frequent as service in the East Bay.

\section{The Kansas City Case}

The MPO for the Kansas City area is the Mid-America Regional Council (MARC). In contrast to Chicago, the initial response from established transit agencies in Kansas City when the opportunity for JARC funding arose was to compete against each other for funding. The JARC funding regulations had specified a single fund- 
ing application come from each region, so the transit agencies still had to work through the MPO rather than to submit separate applications to FTA directly. This presented MARC with a choice of submitting a laundry list of six or seven unrelated projects or trying to present a unified plan that might be more compelling to FTA. MARC attempted the latter approach and, within a month, pulled together a consortium of area transportation providers, municipalities, and social service organizations to create the Kansas City Areawide Job Access Partnership, which became an advisory council under MARC's committee structure. Many of the participants already were members of the Special Transportation committee, which addressed the transportation needs of the elderly and disabled populations in the Kansas City metropolitan area (Special Transportation Advisory Committee 1992). The original members were MARC, the Kansas City Area Transit Authority (KCATA) (Missouri), Unified Government Transit (UGT) (Kansas City, Kansas and Wyandotte County), Johnson County Transit, Full Employment Council, OATS (a rural transportation provider), and Ray County Transit.

In developing the consolidated, multi-year JARC application, MARC officials and committee participants reported that there were already-known transportation needs that were not being addressed and special challenges facing the Kansas City region, if it wished to compete for JARC funding. Despite four transit service providers in the region (KCATA, Johnson County Transit, Ray County Transit, and OATS), there was no dedicated revenue source to fund transit. In addition to making it much harder to develop a funding stream for the local match provision in the JARC application, the participants were concerned about the possibility of implementing services that would then be lost after the federal funding was gone. Thus, there were efforts early on to enlist employer-support for JARC services in an attempt to make the new services self-sustaining.

Metropolitan Kansas City benefitted substantially from the earmarking process. A Kansas congressman liberally earmarked JARC funds for his region. During the five years of the TEA-21-legislated JARC program, he acquired $\$ 2,000,000$ for the Job Access Partnership to support job access transportation in Johnson County and $\$ 4,625,000$ for the Unified Government. He also secured an earmark of $\$ 500,000$ for UG in the reauthorized transportation bill SAFETEA-LU (Mid-America Regional Council 2005).

An official from Unified Government Transit reported that the earmarked funding was used to offset the cost of its annual contract with KCATA for transit service. 
KCATA provides 850,000 passenger trips in Wyandotte County plus transportation between Kansas and Missouri. UGT also participates in the JARC Partnership because of its regional focus, for which it receives $\$ 45,000$ annually. Through 2004, these funds were used for UGT's Joblinks program, which was contracted service to provide transportation to Wyandotte County residents who worked in Johnson County, at locations that either had no bus service or no service during the rider's work shift. About 33,000 annual trips were provided with this service. Recently, the transit service subsidized with JARC funding was shifted to serve an area of Wyandotte County that has a NASCAR track and an adjacent 400 acres that the County has retained for future development. Over 2,500 job opportunities are anticipated in the area.

\section{Discussion}

In Chicago, implementing the various JARC projects turned out to be considerably more challenging than winning the awards. It turned out that few (if any) FTA regulations had been reduced or relaxed for non-traditional providers involved in the projects. This ultimately led to the Regional Transportation Authority acting in an oversight capacity to ensure that all FTA requirements would be met to prevent violations that might result in lost funding. Since this relationship had not been completely worked out prior to the submittal of the JARC grant application, it took time to set it up. Staff turnover at RTA also hampered the implementation of the program. While some JARC funds were expanded in 2000, it was clear that the program was severely delayed, above and beyond the nine month lag that most projects faced. The U.S. DOT noted that by mid 2001, only seven projects had been selected for grants in FY 1999 where the funds had still not been fully obligated, and five of them were in the Chicago area-essentially the entire CATS proposal (Chicago Area Transportation Study 1998).

Chicago was objectively slower in using JARC funds than other metropolitan regions, which might have led to the frustration some grassroots organizations had with the program. The meeting minutes from the Community Mobility Task Force often present grassroots organizations attempting to hold transit agencies responsible for previous JARC obligations. In some cases, pressure from these grassroots organizations appeared to keep a few JARC programs running longer. Nonetheless, the relationship between the transportation planners and the grassroots organizations was somewhat strained over the JARC process, and a certain amount of defensive blame-avoidance was observed. From our research, 
it appears that devoting more effort to maintain and improve these relationships would have not produced more institutional support for innovative JARC projects.

Table 1 indicated that Chicago had the lowest institutional support (at the federal level) of the three MPOs studied. Earmarks were not a high priority for Chicago's Congressional representation, and JARC funding went to other regions with smaller impoverished populations (in absolute and relative terms). The implementation of JARC-funded projects went the most smoothly when run through transit service boards (i.e., between official agencies) and the grassroots efforts stalled. Metra, Pace, and the CTA all were able to report new JARC-supported service on the ground by December 2000.

The lessons learned in Chicago appear to be that non-traditional companies were not well positioned to administer JARC programs on their own or even with the assistance of the RTA. Successful partnerships were possible where a smaller company partnered with CTA, Metra, or Pace.' One potential solution of the Accessto-Jobs program would have been for the FTA to undergo a cultural change, making them more willing to accept nontraditional approaches for addressing welfareto-work barriers (Government Accounting Office 1998). Many observers contend that this cultural shift did not occur and made implementing the program more difficult. Additional institutional support presumably would have allowed RTA to overcome these barriers (as MTC was able to do). In short, MTC was more active than CATS in actively pursuing inter-agency collaboration with grassroots organization. The synergy of inter-agency collaboration gave MTC more institutional support to use JARC funding in a more creative way.

In contrast to Chicago, both the San Francisco Bay Area and Kansas City received large earmarks, indicating considerable institutional support. The respective MPOs had quite different outcomes in terms of success in engaging the grassroots. First, as MTC worked with grassroots organizations, three objectives were identified to address the transportation barriers: (1) "assess the transportation requirements of CalWORKs program participants and identify transportation-related barriers to obtaining and retaining work," (2) "identify strategies to increase availability, affordability, and effectiveness of transportation services," and (3) "establish agreements among the transportation providers, employers and Social Services Agency (SSA) to ensure the availability of Transportation options" (Stewart 1999). As mentioned previously, MTC recognized that traditional public transit services could not solve all the transportation needs for welfare recipients. MTC was the 
only region that worked aggressively with grassroots organizations to sponsor several non-traditional transportation projects with JARC funds (e.g., car programs and vanpool programs). The strong grassroots support allowed MTC to create innovative, non-traditional transportation programs to meet the unorthodox transportation needs of welfare-to-work recipients.

It is important to note that although MTC considered the LIFT program to be a success, it expressed concern about institutional and programmatic barriers that interfered with the coordination of welfare-to-work and job access programs. MTC consistently encountered programmatic barriers, a lack of flexibility in JARC guidelines, and a failure by FTA to answer questions regarding JARC guidelines in an appropriate time-frame. As far as the institutional barriers were concerned, MTC found that it was difficult to maintain momentum with welfare-to-work plans. MTC applauded JARC's focus on coordination but found it difficult to coordinate JARC activities with a diverse group of grassroots organizations providing services for CalWORK recipients. Trying to coordinate with a diverse group was time-consuming, and it was difficult to build consensus, given that the organizations have different goals. Despite these challenges, MTC and the grassroots organizations worked to create innovative programs that could be implemented.

In the Kansas City region, grassroots support was missing. In the first round of JARC funding, no grassroots organizations were reported to have requested JARC funding. In fact, there was no RFP process in the Kansas City region to invite groups that did not have a seat on the committee to participate in the JARC program until Year 4, for which the Partnership set aside 20 percent of the JARC funds for new projects. The co-chair of the Special Transportation Committee reported that by the second application (second two-year program), the Partnership knew where to beef up existing services because of the variety of interests on the committee. By this time, the committee had more consumer representation, and the JARC Partnership and the committee that previously focused on senior citizens and the disabled population merged into a single Special Transit Committee, greatly expanding the number of participants. The MPO and all but one member of the committee could list no grassroots organizations that pushed for JARC funding. Much of the transportation advocacy work in the area has been in reference to encouraging legislators to create a stable funding source for transit or advocating for light rail. Such organizations include the Regional Transit Alliance and Citizens for Modern Transit. In contrast to the situations in Chicago and San Francisco, community groups in Kansas City did not play an active role in putting 
the proposal together nor watching over how the funds were spent. In general, community groups did not take an active role in following or trying to influence planning decisions taken by MARC.

One group did try to fill the role of a grassroots organization, the Local Investment Commission (LINC), a community collaborative that works to improve the lives of children and families in Jackson County. It is important to note that LINC worked with community-based agencies that were seeking JARC funds, served in an advisory role to the committee, and provided matching funds for community groups, whose projects had been implemented. LINC also worked with Ford and community programs to help low-income workers obtain loans for autos. Based on the Kansas City case, we modified our first hypothesis to indicate that institutional support is a necessary, but not sufficient, condition for innovation. The MPO had considerable support on the JARC issue and should have been able to work with any partner, but it was not met with any offers to establish non-traditional transit service. As illustrated in Figure 1, San Francisco was the only region that had high institutional and high grassroots support. Chicago had high grassroots support but insufficient institutional support. Kansas City had high institutional support but lacked grassroots support.

\section{Conclusions}

We framed this paper around two issues: (1) institutional support and (2) grassroots support. Our analysis shows the Chicago, Kansas City, and San Francisco MPOs responded in different ways. We believe that the policy outcomes reflected the intensity of institutional and grassroots support to use JARC as an opportunity to create innovative transportation programs for low-income populations. In regards to our analytical typology of support, MTC was the only region with high institutional and grassroots support; thus, it was in a unique position to actively pursue private mobility programs for low-income families. Although these programs were discussed for the Chicago region, CATS did not provide the type of institutional support that MTC provided. Although the Kansas region had the institutional support for such creativity, it lacked the grassroots support for private mobility programs. In fact, MTC's support for these car-sharing programs showed that they recognized that the structural barriers could not be overcome by fixed transit service. By recognizing that public transit was simply not flexible 
enough to meet all the needs of CalWORK recipients, MTC opened an important avenue of private mobility services that, in the long-run, foster a policy environment that is conducive to sustainable economic self-sufficiency. MTC's vision reflects the new collective rationality that investing in private mobility programs is a greater good than continually investing in public transit programs where there is no long-term bang for the buck.

Finally, alone among the MPOs we studied, MTC spearheaded an effort to create a regional JARC program to allow smaller non-traditional transportation providers to apply for federal money. MTC created social processes in which some authority and project management was given to grassroots organizations. Thinking more broadly about creativity, institutional creativity often requires sufficient funding (that has not been narrowly restricted to particular uses), and in the later fiscal years of the JARC program, the rules had changed to the point where substantial funding was only available when there was high institutional support from national-level politicians. While the institutional support appears to be a necessary condition, it is not sufficient, or more innovation would have occurred in Kansas City. The combination of institutional and grassroots support was what allowed MTC to be the most innovative region.

\section{End Notes}

${ }^{1}$ Policy experts warned that transportation was not a panacea to lower welfare rates. Other needs, such as access to child care or basic skill training, are just as crucial for welfare recipients as they try to find jobs (see Wachs and Taylor 1998).

${ }^{2}$ See Douglas (1986) for an expanded discussion of rational choice theory and functional theory.

${ }^{3}$ Bureaucratic agencies (or rather, the bureaucrats staffing them) are often motivated more by blame-avoidance than the more positive (and potentially constructive) credit-seeking role that can be activated by public support for new policies and programs (Lee 1994). Indeed, it is worth considering whether innovation in itself is likely to provoke blame-avoidance as a preemptive strategy and what may be done to limit this response.

${ }^{4}$ The process of instituting the Community Mobility Task Force began in June 1997, but it took several months to determine its composition. The Task Force is unique among CATS' working groups, since it is the only one to be chaired (in fact, 
co-chaired) by citizen representatives rather than a representative of the government or a transportation provider. This structure was requested by a variety of community and environmental groups in Chicago.

${ }^{5}$ Scholars have found that the 376 line cost $\$ 7$ per passenger trip versus a fare of $\$ 1.50$ (Sööt et al. 2002).

${ }^{6}$ Reverse commute programs that are measured on ridership (rather than people removed from welfare rolls) will inevitably spend more resources chasing potential riders as the original riders opt out of the service after a few months of employment when they are able to buy a car (Petersen and Sermons 1996).

7 The DuPage Federation, which had earmarks in all years after FY 1999, did work with smaller companies.

\section{References}

Altshuler, A. A. , and R. D. Behn, eds. 1997. Innovation in American Government: Challenges, Opportunities, and Dilemmas. Edited by A. A. Altshuler and R. D. Behn. Washington D.C.: Brookings Institution Press.

Blumenberg, E. 2000. Moving welfare participants to work: Women, transportation, and welfare reform. Affilia 15(2): 259-276.

Blumenberg, E., D. Miller, M. Garrett, L. Schweitzer, K. Kitsis, M. Manville, and B. Mallavarapu. 2003. California transportation needs assessment: The transportation barriers and needs of welfare recipients and low-wage workers. The Ralph \& Goldy Lewis Center for Regional Policy Studies, UCLA School of Public Policy and Social Research.

Blumenberg, E. 2002. Planning for the transportation needs of welfare participants: Institutional challenges to collaborative planning. Journal of Planning Education and Research 22(2): 152-163.

Blumenberg, E., and M. Manville. 2004. Beyond the spatial mismatch: Welfare recipients and transportation policy. Journal of Planning Literature 19(2): 182205.

Blumenberg, E., and L. Schweitzer. 2006. Devolution of transport policy for the working poor: The case of the U.S. Job Access and Reverse Commute Program. Planning Theory and Practice 7: 7-25. 
Cervero, R. 2004. Job isolation in the U.S.: Narrowing the gap through Job Access and Reverse-Commute Programs. In Running on Empty: Transport, Social Exclusion and Environmental Justice, edited by K. Lucas. Bristol, UK: Policy Press.

Cervero, R., J. O. Sandoval, and J. Landis. 2002. Transportation as a stimulus of welfare-to-work: Private versus public mobility. Journal of Planning Education and Research 22: 50-63.

Cervero, R., and Y. Tsai. 2003. Job access and reverse commute initiatives in California: A review and assessment. Transportation Research Record 1859: 76-86.

Cervero, R., Y. Tsai, M. Wachs, E. Deakin, J. Dibb, A. Kluter, C. Nuworsoo, I. Petrova, and M. Pohan. 2002. Reverse commuting and job access in California: Markets, needs, and policy prospects. In Institute of Transportation Studies. UCBITS-RR-2002-7 Berkeley, CA.

Chicago Area Transportation Study. 1998. Regional job access and reverse commute transportation plan and grant application for Northeastern Illinois. Chicago.

DiMaggio, P. L., and W. W. Powell. 1991. The iron cage revisited: Institutional isomorphism and collective rationality in organizational fields. In The New Institutionalism In Organizational Analysis, edited by W. W. Powell and P. L. DiMaggio. Chicago, IL: The University of Chicago Press.

Douglas, M. 1986. How Institutions Think. Syracuse, NY: Syracuse University Press.

Fol, S., G. Dupuy, and O. Coutard. 2007. Transport policy and the car divide in the UK, the U.S. and France: Beyond the environmental debate. International Journal of Urban and Regional Research 31 (4):802-812.

Forester, J. 1989. Planning in the Face of Power. Berkeley, CA: University of California Press.

Gomez Ibanez, J. 1984. Transportation and the poor. In The State and the Poor in the 1980, edited by M. Carballo and M. J. Bane. Boston, MA: Auburn House.

Government Accounting Office. 1998. Welfare reform: Implementing DOT's Access to Jobs Program. In GAO RCED 99-36.

Government Accounting Office. 1998. Welfare reform: Transportation's role in moving from welfare to work. In GAO RCED 98-161. 
Government Accounting Office. 1999. Welfare reform: Implementing DOT's Access to Jobs Program in its first year In GAO RCED 00-14.

Kasarda, J. 1988. Jobs, migration, and emerging urban mismatches. In Urban Change and Poverty, edited by M. McGeary, G. H. and L. E. Lynn. Washington, DC: National Academy Press.

Lee, S. 1994. Policy type, bureaucracy, and urban policies: Integrating model of urban service distribution. Policy Studies Journal 22: 87-108.

Lieberman, R. C., and G. M. Shaw. 2000. Looking inward, looking outward: The politics of state welfare innovation under devolution. Political Research Quarterly 53(2): 215-240.

Lucas, M. T., and C. F. Nicholson. 2003. Subsidized vehicle acquisition and earned income in the transition from welfare to work. Transportation 30(4).

Mid-America Regional Council. 2005. Congressman Dennis Moore secures funds to provide job access and reverse commute services for region. MARC 2005 [cited February 10 2005].

O'Regan, K., and J. Quigley. 1998. Cars for the poor. Access 12.

Ong, P., and E. Blumenberg. 1998. Job access, commute and travel burden among welfare recipients. Urban Studies 25(1): 77-93.

Ong, P. 1996. Work and automobile ownership among welfare recipients. Social Work Research 20(4): 193-288.

Ortoleva, S., and M. Brenman. 2004. Women's issues in transportation. In Running on Empty: Transport, Social Exclusion and Environmental Justice, edited by K. Lucas. Bristol, UK: Policy Press.

Petersen, E., and M. Sermons. 1996. Evaluating reverse commute programs in Chicago. In Metropolitan Conference on Public Transportation Research. Chicago.

Raphael, S., and L. Rice. 2002. Car ownership, employment, and earnings. Journal of Urban Economics 52: 109-130.

Sanchez, T. W., Q. Shen, and Z. R. Peng. 2004. Transit mobility, jobs access, and low-income labor participation in U.S. Metropolitan Areas. Urban Studies 41(7): 1313-1331. 
Sanchez, T.W., R. Stolz, and J. Ma. 2003. Moving to equity: Addressing inequitable effects of transportation policies on minorities. Cambridge, MA: The Civil Rights Project at Harvard University.

Sanchez, T. W., and L. Schweitzer. 2008. Assessing federal employment accessibility policy: An analysis of the JARC Program. In Metropolitan Policy Program. Washington D.C.: Brookings.

Schram, S. F. 1998. Introduction to welfare reform: A race to the bottom. Publius 28(3): 1-7.

Singh, J. V., D J. Tucker, and A. G. Meinhard. 1991. Institutional change and ecological dynamics. In The New Institutionalism In Organizational Analysis, edited by W. W. Powell and P. L. DiMaggio. Chicago, IL: The University of Chicago Press.

Sööt, S., P. Sriraj, and P. Thakuriah. 2002. A user survey of transportation services funded by the Job-Access-Reverse-Commute Program. Chicago, IL: Urban Transportation Center.

Special Transportation Advisory Committee. 2005. Memorandum. MARC, March 5, 20051992 [cited March 5 2005].

Stewart, L. 1999. Welfare to work: The transportation issue. Bay Area Monitor.

Wachs, M., and B. D. Taylor. 1998. Can transportation strategies help meet the welfare challenge? Journal of the American Planning Association 64(1): 15-19.

Weber, M. [1922] 1978. Economy and Society. Berkeley, CA: University of California Press.

\section{About the Authors}

J.S. OnÉsimo Sandoval (jsandov3@slu.edu) is an Assistant Professor in the Department of Sociology and Criminal Justice. He received his Ph.D. from the University of California, Berkeley.

ERIC Petersen (petersene@comcast.net) is an Associate at Cambridge Systematics. He received his Ph.D. from Northwestern University.

KıM L. HUNT (Hunt.kim@sbcglobal.net) is a principal with the O-H Community Partners, Ltd. 